\title{
Front Matter: Volume 10610
}

\begin{abstract}
, "Front Matter: Volume 10610," Proc. SPIE 10610, MIPPR 2017: Parallel Processing of Images and Optimization Techniques; and Medical Imaging, 1061001 (6 March 2018); doi: 10.1117/12.2316403
\end{abstract}

SDIE Event: Tenth International Symposium on Multispectral Image Processing and Pattern Recognition (MIPPR2017), 2017, Xiangyang, China 


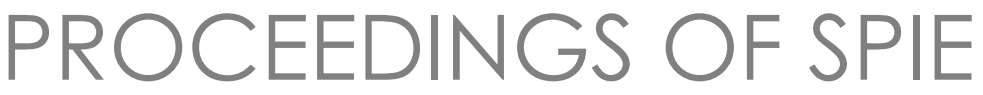

\title{
MIPPR 2017: Parallel Processing of Images and Optimization Techniques; and Medical Imaging
}

\author{
Hong Sun \\ Henri Maitre \\ Bruce Hirsch \\ Editors
}

\section{8-29 October 2017 \\ Xiangyang, China}

Organized by

Huazhong University of Science and Technology (China)

Hubei University of Arts and Sciences (China)

Sponsored by

National Key Laboratory of Science and Technology on Multi-spectral Information Processing (China)

Huazhong University of Science and Technology (China)

Hubei University of Arts and Sciences (China)

Hubei Association of Automation (China)

Published by

SPIE 
The papers in this volume were part of the technical conference cited on the cover and title page. Papers were selected and subject to review by the editors and conference program committee. Some conference presentations may not be available for publication. Additional papers and presentation recordings may be available online in the SPIE Digital Library at SPIEDigitalLibrary.org.

The papers reflect the work and thoughts of the authors and are published herein as submitted. The publisher is not responsible for the validity of the information or for any outcomes resulting from reliance thereon.

Please use the following format to cite material from these proceedings:

Author(s), "Title of Paper," in MIPPR 2017: Parallel Processing of Images and Optimization Techniques; and Medical Imaging, edited by Hong Sun, Henri Maître, Bruce Hirsch, Proceedings of SPIE Vol. 10610 (SPIE, Bellingham, WA, 2018) Seven-digit Article CID Number.

ISSN: 0277-786X

ISSN: 1996-756X (electronic)

ISBN: 9781510617230

ISBN: 9781510617247 (electronic)

Published by

SPIE

P.O. Box 10, Bellingham, Washington 98227-0010 USA

Telephone +1 3606763290 (Pacific Time) · Fax +1 3606471445

SPIE.org

Copyright (c) 2018, Society of Photo-Optical Instrumentation Engineers.

Copying of material in this book for internal or personal use, or for the internal or personal use of specific clients, beyond the fair use provisions granted by the U.S. Copyright Law is authorized by SPIE subject to payment of copying fees. The Transactional Reporting Service base fee for this volume is $\$ 18.00$ per article (or portion thereof), which should be paid directly to the Copyright Clearance Center (CCC), 222 Rosewood Drive, Danvers, MA 01923. Payment may also be made electronically through CCC Online at copyright.com. Other copying for republication, resale, advertising or promotion, or any form of systematic or multiple reproduction of any material in this book is prohibited except with permission in writing from the publisher. The CCC fee code is 0277$786 \mathrm{X} / 18 / \$ 18.00$.

Printed in the United States of America.

Publication of record for individual papers is online in the SPIE Digital Library.

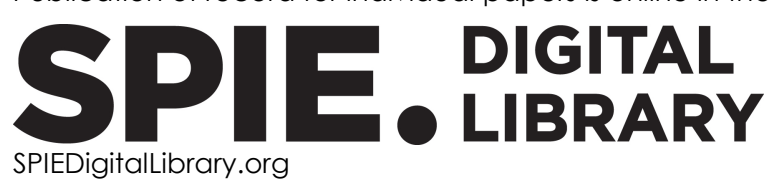

Paper Numbering: Proceedings of SPIE follow an e-First publication model. A unique citation identifier (CID) number is assigned to each article at the time of publication. Utilization of CIDs allows articles to be fully citable as soon as they are published online, and connects the same identifier to all online and print versions of the publication. SPIE uses a seven-digit CID article numbering system structured as follows:

- The first five digits correspond to the SPIE volume number.

- The last two digits indicate publication order within the volume using a Base 36 numbering system employing both numerals and letters. These two-number sets start with 00, 01, 02, 03, 04, 05, 06, 07, 08, 09, 0A, OB ... 0Z, followed by 10-1Z, 20-2Z, etc. The CID Number appears on each page of the manuscript. 


\title{
Contents
}

\author{
$\checkmark \quad$ Authors \\ vii Symposium Committee \\ xi Introduction
}

PARALLEL PROCESSING OF IMAGES AND OPTIMIZATION

1061002 A fast method for single image haze removal based on multiscale dark channel prior [10610-102]

1061003 A GPU-based mipmapping method for water surface visualization [10610-104]

1061004 Hardware-efficient implementation of digital FIR filter using fast first-order moment algorithm [10610-106]

1061005 Simulation and analysis of traffic flow based on cellular automaton [10610-107]

1061006 A novel configurable VLSI architecture design of window-based image processing method [10610-111]

1061007 Novel structures for Discrete Hartley Transform based on first-order moments [10610-112]

1061008 Route constraints model based on polychromatic sets [10610-113]

1061009 Analysis of parameter estimation and optimization application of ant colony algorithm in vehicle routing problem [10610-115]

MEDICAL IMAGING

10610 OA A threshold-based fixed predictor for JPEG-LS image compression [10610-2]

10610 OB A block-based JPEG-LS compression technique with lossless region of interest [10610-3]

10610 OC Sparse representations via learned dictionaries for $\mathbf{x}$-ray angiogram image denoising [10610-4]

10610 OD Research on segmentation based on multi-atlas in brain MR image [10610-5]

10610 OE Application of deep learning in the identification of TAO [10610-6] 
Proc. of SPIE Vol. $106101061001-4$ Downloaded From: https://www.spiedigitallibrary.org/conference-proceedings-of-spie on 25 Apr 2023
Terms of Use: https://www.spiedigitallibrary.org/terms-of-use 


\title{
Authors
}

\begin{abstract}
Numbers in the index correspond to the last two digits of the seven-digit citation identifier (CID) article numbering system used in Proceedings of SPIE. The first five digits reflect the volume number. Base 36 numbering is employed for the last two digits and indicates the order of articles within the volume. Numbers start with 00, 01, 02, 03, 04, 05, 06, 07, 08, 09, 0A, OB...0Z, followed by 10-1Z, 20-2Z, etc.
\end{abstract}

\author{
Cai, Chao, 08 \\ Cao, Li, 04 \\ Cao, Yu-Wei, 09 \\ Deng, Lihua, OA, OB \\ Hong, Hanyu, 02 \\ Hua, Xia, 02 \\ Huang, Zhenghua, $\mathrm{OA}, \mathrm{OB}$ \\ Huang, Zhenghua, OC \\ Jin, Jicheng, $\mathrm{OE}$ \\ Li, Dongwu, 08 \\ Li, Hua, 03 \\ Li, Qian, 0C \\ Liu, Jianguo, 04, 07 \\ Liu, Xia, 05 \\ Liv, Zhao, 02 \\ Qian, Yuejing, OD \\ Quan, Wei, 03 \\ Ren, Xianping, 05 \\ Sang, Hongshi, 06 \\ Shang, Jingfan, $0 \mathrm{C}$ \\ Shen, Xubang, 06 \\ Shi, Yu, 02 \\ Wang, Hao, 07 \\ Wang, Houjun, 08 \\ Wu, Cong, OE \\ Wu, Yan, 03 \\ Xiong, Jun, 04 \\ Xiong, Jun, 07 \\ $\mathrm{Xu}, \mathrm{Chao}, 03$ \\ Xu, Quan-Li, 09 \\ Yang, Kun, 09 \\ Yao, Shoukui, OA, OB \\ Yin, Xianjun, 08 \\ Zhang, Jing, 04 \\ Zhang, Tianxu, OC \\ Zhao, Hui, 06 \\ Zheng, Wenjuan, 07
}


Proc. of SPIE Vol. $106101061001-6$

Downloaded From: https://www.spiedigitallibrary.org/conference-proceedings-of-spie on 25 Apr 2023 Terms of Use: https://www.spiedigitallibrary.org/terms-of-use 


\title{
Symposium Committee
}

\author{
Symposium Chairs
}

M. V. Srinivasan, University of Queensland (Australia)

Deren Li, Wuhan University (China)

Program Committee Chairs

Bir Bhanu, University of California at Riverside (United States)

Tianxu Zhang, Huazhong University of Science and Technology

(China)

Program Committee

Christian Bauckhage, IAIS Fraunhofer (Germany)

Bir Bhanu, University of California, Riverside (United States)

Zhiguo Cao, Huazhong University of Science and Technology (China)

Chunqi Chang, Shenzhen University (China)

C. H. Chen, University of Massachusetts (United States)

Xinjian Chen, Soochow University (China)

Jinkui Chu, Dalian University of Technology (China)

Melba M. Crawford, Purdue University (United States)

Armin B.Cremers, Universität Bonn (Germany)

Mingyue Ding, Huazhong University of Science and Technology

(China)

Aaron Fenster, The University of Western Ontario (Canada)

Wei Guo, Hebei Normal University (China)

Bruce Hirsch, Drexel University (United States)

Horace H.S. Ip, City University of Hong Kong (Hong Kong, China)

Jun Jo, Griffith University (Australia)

Irwin King, Chinese University of Hong Kong (Hong Kong, China)

Vladimir G. Krasilenko, Vinnitsa Social Economy Institute (Ukraine)

Deren Li, Wuhan University (China)

Xuelong Li, University of London (United Kingdom)

Qiang Li, University of Chicago (United States)

Senhu Li, Xoran Technologies LLC (United States)

Stan Z. Li, Chinese Academy of Sciences (China)

Xingde Li, Johns Hopkins University (United States)

Guoying Liu, Anyang Normal University (China)

Jianguo Liu, Huazhong University of Science and Technology (China)

Xia Liu, Jianghan University (China)

Hanqing Lu, Institute of Automation (China) 
Henri Maître, École Nationale Supérieure des Télécommunications

(France)

Jiangqun Ni, SunYat-sen University (China)

Laszlo Nyul, University of Szeged (Hungary)

Shaohua Qu, Hubei University of Arts and Science (China)

Jonathan Roberts, Autonomous Systems Laboratory CSIRO ICT Centre (Australia)

Punam K. Saha, University of lowa (United States)

Nong Sang, Huazhong University of Science and Technology (China)

Xubang Shen, Chinese Academy of Sciences (China)

M. V. Srinivasan, University of Queensland (Australia)

Hong Sun, Wuhan University (China)

Katarina Svanberg, Lund University (Sweden)

Jianjun Tan, Hubei University for Nationalities (China)

Dacheng Tao, Nanyang Technological University (Singapore)

Hengqing Tong, Wuhan University of Technology (China)

J. K.Udupa, University of Pennsylvania (United States)

Jinxue Wang, SPIE (United States)

Baoming Wu, Third Military Medical University (China)

Kai Xie, Beijing Institute of Graphic Communication (China)

Weichao Xu, Guangdong University of Technology (China)

Pingkun Yan, Philips Research North America (United States)

Yuan Yuan, Aston University (United Kingdom)

Liangpei Zhang, Wuhan University (China)

Jun Zhang, Waseda University (Japan)

Tianxu Zhang, Huazhong University of Science and Technology

(China)

Sheng Zheng, China Three Gorges University (China)

Yanfei Zhong, Wuhan University (China)

Jie Zhou, Tsinghua University (China)

Organizing Committee Chairs

Jianguo Liu, Huazhong University of Science and Technology (China)

Co-organizing Committee Chairs

Shaohua Qu, Hubei University of Arts and Science (China)

Hongyan Wang, Huazhong University of Science and Technology

(China) 
General Secretary

Faxiong Zhang, Huazhong University of Science and Technology (China)

Associated General Secretary

Xiaofeng Yue, Huazhong University of Science and Technology (China)

Secretaries

Zhihua Ban, Huazhong University of Science and Technology (China) Yuanchun Xia, Huazhong University of Science and Technology (China)

Jun Xiong, Huazhong University of Science and Technology (China) Jie Chen, Huazhong University of Science and Technology (China) Min Du, Huazhong University of Science and Technology (China) Shanjun Li, Huazhong University of Science and Technology (China) 
Proc. of SPIE Vol. 10610 1061001-10 Downloaded From: https://www.spiedigitallibrary.org/conference-proceedings-of-spie on 25 Apr 2023
Terms of Use: https://www.spiedigitallibrary.org/terms-of-use 


\section{Introduction}

Welcome to the proceedings from the 10th International Symposium on Multispectral Image Processing and Pattern Recognition (MIPPR 2017), held 28-29 October 2017 in Xiangyang, China.

MIPPR focuses mainly on latest research in multispectral image processing and pattern recognition. The symposium has a broad charter. Multispectral is interpreted not just multiple-wavelength in a narrow sense but also multi-sensor, multi-modal, and multimedia. It covers many disciplines such as sensing, image processing, computer vision, pattern recognition and involves the development of efficient processing algorithms and their optimization and implementation. The wide range of applications considered in this symposium include automatic target recognition, autonomous navigation, medical image processing, remote sensing, geographic information systems and many others.

The symposium provides a forum for scientists, professors, engineers and graduate students from universities, industries and government laboratories to meet and exchange ideas and discuss theories, techniques, algorithms and applications in multispectral image processing and pattern recognition. As expected, there were ample discussions both inside and outside the lecture halls helping to make MIPPR 2017 an exciting meeting.

In response to the call for papers, we received 231 submissions. Based on the reviews provided by an excellent program committee we accepted 193 papers covering many aspects of multispectral image processing and pattern recognition. To ensure a high-quality conference, all abstracts and proceedings of SPIE papers are reviewed by peers for technical merit and English expression. The conference proceedings from MIPPR 2017 consist of five volumes which will be included on the SPIE Digital Library:

- MIPPR 2017: Multispectral Image Acquisition, Processing, and Analysis (SPIE Volume 10607)

- MIPPR 2017: Automatic Target Recognition and Navigation (SPIE Volume 10608)

- MIPPR 2017: Pattern Recognition and Computer Vision (SPIE Volume 10609)

- MIPPR 2017: Parallel Processing of Images and Optimization Techniques; and Medical Imaging (SPIE Volume 10610)

- MIPPR 2017: Remote Sensing Image Processing, Geographic Information Systems, and Other Applications (SPIE Volume 10611).

The realization of a conference depends upon the hard work of many dedicated people. We would like to thank all the members of the organizing committee who 
put together this symposium for the benefit of all the researchers. They are responsible for making this conference a success. We hope the papers and the research results presented at this conference will inspire new research in all the areas related to multispectral image processing and pattern recognition.

Bir Bhanu 